\title{
Planning and management strategies in tourist areas: guidelines for a sustainable development of the Durres Bay district
}

\author{
C. Cosmi, S. Fiore \& P. Ragone \\ National Council of Research - Institute of Methodologies for \\ Environmental Analysis CNR-IMAA, Italy
}

\begin{abstract}
In the framework of the LIFE project "Capacity Building for Sustainable Tourism Development - CBSTD", a general purpose methodology was defined to promote sustainable tourism activities based on an integrated development of the territory. The central issues were to valorise the endogenous resources and to encourage a participative process among citizens, stakeholders and decision makers, by identifying key objectives for a sustainable development of the whole territory, in actuation of local Agenda 21. The methodological approach is based on the integration of two methodologies, the "Carrying Capacity AssessmentCCA" and the IEA- ETSAP "Advanced Local Energy Planning - ALEP", which is widely used in different contexts. The analysis of the study area pointed out that tourism strategies development should keep up with the implementation of plans for the revitalization of the territory, promoting major investments in infrastructures. The methodology can be applied in a broad variety of situations and is finalised to the identification and elimination of bottlenecks for the attribution of certified environmental labels by public and private owners.
\end{abstract}

Keywords: sustainable tourism, carrying capacity assessment, ALEP methodology, integrated territorial planning.

\section{Introduction}

Tourism represents an increasing economic resource for many countries, especially potential EU candidate countries, to be developed with a precautionary approach aimed at increasing the benefits to the local population 
and economy and also limiting any potential damage to the environment and cultural heritage [1]. Each tourist area is characterised by a specific carrying capacity that is commonly defined as "...the maximum number of people that may visit a tourist destination at the same time, without causing destruction of the physical, economic and socio-cultural environment and an unacceptable decrease in the quality of the visitors' satisfaction." The evaluation of the carrying capacity of a tourist area therefore should take into account both the environmental and socio-economic implications [2].

The UNEP guidelines indicate the Carrying Capacity Assessment (CCA) evaluation as "a main tool for planning and management strategies in the tourist areas", being based on analytical methodologies that consider as fundamental components the environmental and urban features of the investigated areas, the typology and capacity of tourism attractions, the relationships among sectors, the local and national tourism policies, the preferences of tourists, local population and tour operators [3].

The main purpose of sustainable tourism is then to find a path towards an economic and ecological sustainable development of local systems while also taking into account limited financial and human resources as well as incomplete insight into the future development of economic, technical and social conditions. In this framework, the integration of CCA evaluation methodology [3], with energy-environmental planning, allows developing integrated territorial plans in a broader sustainability perspective. In this framework the Advanced Energy Planning methodology (ALEP) [5], carried out under the aegis of International Energy Agency - IEA, could give a fundamental contribution to the development of robust "comprehensive" long term strategies established by all the relevant groups of interest.

\section{Methodology}

In the framework of the LIFE project "Capacity Building for Sustainable Tourism Development - CBSTD", a general purpose methodology was defined and implemented for the assessment of tourist sites (Figure 1) [6]. This methodology is based on the integration of CCA evaluation, the most used tool for tourism management [3, 4], and the "Advanced Local Energy Planning (ALEP)" set up under the aegis of the International Agency of Energy in the framework of the Implementing Agreement on Energy Conservation in Buildings and Community Systems (ECBCS) - Annex 33 "Advanced Local Energy Planning -ALEP" and widely applied in local case studies with different objectives and boundary conditions $[5,7]$.

The methodological approach is focused on the integrated assessment of the territory for the exploitation of tourism activities in a sustainable framework. Therefore, the main steps are addressed to:

- Evaluate the background on which the tourism activities are developed, identifying the main criticalities concerning resources, infrastructures and environment 


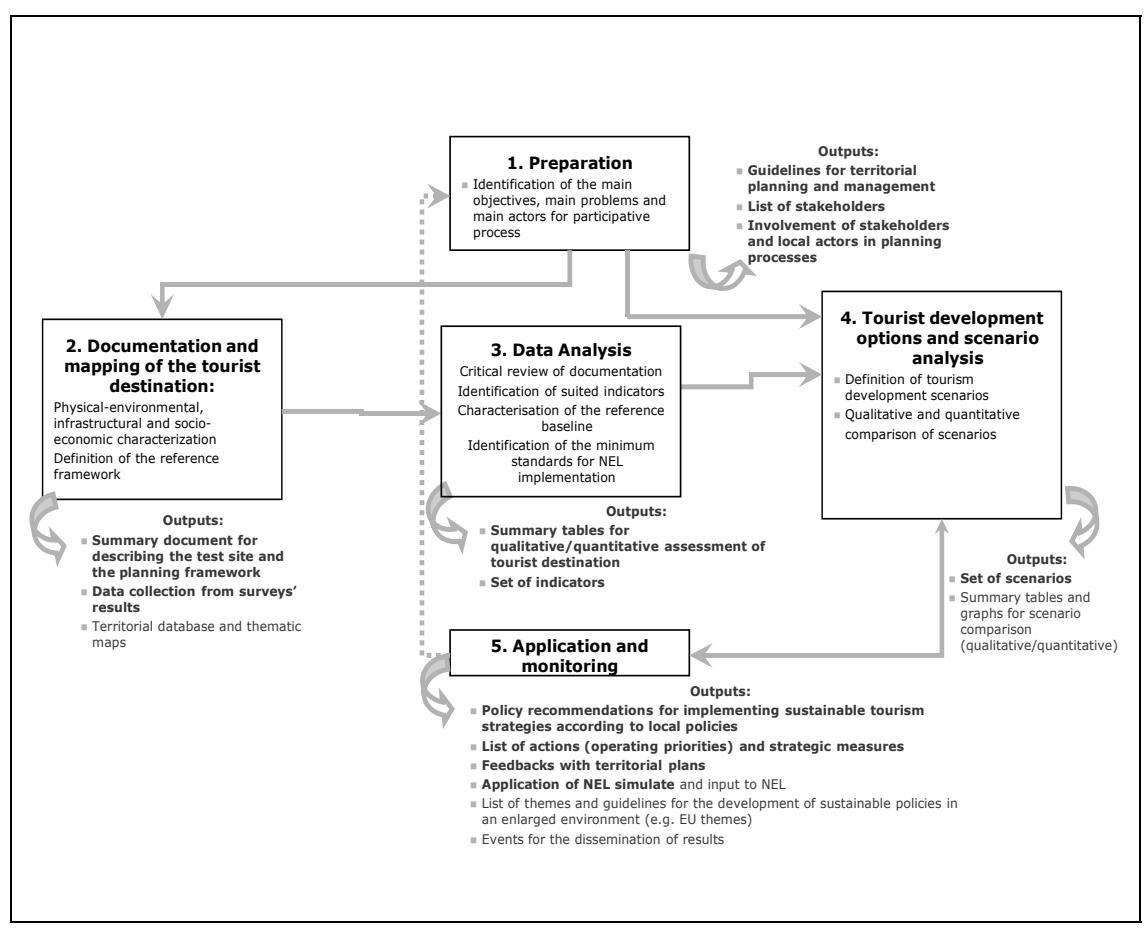

Figure 1: $\quad$ Main phases of the methodology.

- Individuate the crucial parameters for the area under investigation, in order to have a quantitative and qualitative evaluation of the state of art and to monitor the impact of tourism activities

- Define the carrying capacity as the maximum (optimal) number of tourists compatible with environmental quality and services standards, taking into account the physical limits, the reference framework and the motivation of resident population

- Define the optimal scenario for the development of tourism activities that allows the improvement of infrastructures, a better use of natural/urban areas, the improvement of environmental quality, the valorization of cultural heritage as well as the increase of wealth for local population

- Monitor the effectiveness of interventions also by environmental certification.

To this aim, some main phases can be identified as illustrated in Figure 1. The "Preparation" phase focuses on the planning background: key objectives, expected benefits for the local community, main problems that could be encountered, planning horizon, available financial resources and ongoing initiatives. Moreover, for a successful implementation of tourism activities and to increase the social acceptance of strategies, a stakeholder reference group can be defined, identifying the main actors on local and national level, their role and responsibilities as well as the expected feedback on the planning process. 
The "Documentation" phase is aimed to perform an in-depth characterisation of the tourist destination concerning socio-economic, infrastructural and environmental aspects. This characterisation should consider the fundamental components in evaluating the carrying capacity of a territory, namely the physical, environmental, infrastructural, and socio-economic features. Data collected can be organised in a territorial database that ease their management and representation by thematic maps, making information available for further elaborations and study reports.

The "Data Analysis" phase is concerned with a critical review of collected information to assess the state of the art, to point out the sectors that need further investigation as well as the weakness and strength points for the development of tourism activities. A main issue is the identification of parameters for a synthetic evaluation of the environmental and socio-economic framework as well as for the comparison of the effects of different tourism strategies (scenario analysis). Both qualitative and quantitative estimations can be performed, depending on data availability and on the investigated features. A broad participative process involving the main local actors (stakeholders, hoteliers, etc.) is envisaged for the selection of suited indicators.

Three types of indicators could be considered to evaluate the impact of tourism activities:

- Guidance parameters

- Environmental parameters

- Socio-economic parameters

The guidance parameters determine the variations of the other parameters and, according to CCA, could be used to characterise the scenarios. Examples of such parameters are: number of residents, number of tourist per season, tourist presences, number of bed spaces per category.

The environmental and socio-economic parameters emphasize the impact of tourism in terms of pressure on the community and natural resources as well as the environmental damage. The European Environmental Agency core set of indicators (CSI) $[8,9]$ contains a selection of parameters grouped by topics that take into account the most important features to be investigated for the environmental sustainability assessment.

The impact of tourism on local economy and population can be evaluated in terms of tourist intensity (ratio of number of tourist to resident population), tourist density (per capita average square meters of beach available) or evaluating the benefits in terms of specific economic parameters (added value, number of employed), to highlight the tourist fluxes in terms of pressure on resident population, reception structures and increase of wealth and occupation.

Synthetic tables and cause-effects diagrams are useful in this phase for a qualitative assessment that highlight the criticalities as well as the strength points for the development of tourism activities, pointing out the major causes of anthropogenic pressure [10].

The evaluation of the carrying capacity of the territory is aimed to assess the maximum number of tourists compatible with the physical features of the area, 
the reference socio-economic framework and the motivation of resident population.

The subsequent "Scenario Analysis" phase is addressed to define the longterm strategies for expansion of tourism activities in order to achieve a steady economic development, an improved environmental quality and a decreasing tourist intensity. A baseline scenario should be defined to set the reference framework and to compare alternative development pathways in terms of selected indicators. The scenario analysis allows identifying the main thematic areas for the development of sustainable policies in agreement with the main EU Directives (e.g. on biodiversity, energy, water, soil, waste disposal, air quality, natural and cultural heritage, socio-economic development, urban environment, etc.) and the specific objectives to be pursued taking into account the territorial features.

The "Application and Monitoring" phase is addressed to the formulation of policy recommendations and operative priorities for tourism development as well as to identify the measures and tools for their implementation. In this phase it is important to valorise the feedback with territorial plans, taking advantage from ongoing initiatives with common objectives. Monitoring actions should be finally aimed to verify stepwise the effectiveness of the projected strategies and provide feedback for improvements as well as to assess the achievement of high quality standards concerning environmental and energy performances in a broader sustainability perspective.

\section{Socio-economic and environmental characterisation of the case study}

An in-depth preliminary characterisation of the tourism's flows and tourists behaviour as well as the territory was carried out by utilising ad-hoc questionnaires and was completed by a subsequent on-site examination $[11,12]$.

The report on tourism dynamics drafted by the team of Economic Faculty, University of Tirana [11], analysed the geographical features of the Durres Bay, the legal and institutional framework, the basic characteristics of tourist demand and the main problems affecting the tourism carrying capacity.

In general, it was observed an increasing number of visitors arrivals in Albania between 2005 and 2008 with a peak in July-August $2008(+21 \%$ compared to the year $2007,+43 \%$ respect to the year 2006 and $+76 \%$ compared to 2005) (Figure 2) [13].

Balkan countries dominate the market. The largest number of visitors belongs to Macedonia with 26\%, Kosovo 25\% and Montenegro 8\%. Meanwhile other European countries cover around 19\% of the tourist arrivals in 2008 [13].

The Durres region is a priority area for tourism development due to its strategic position, located nearby the most important harbour of the country, the unique national airport. Moreover, it accounts for $23 \%$ of the total hotel accommodation capacity of the country, being a site with interesting archaeological, historical and natural resources. 


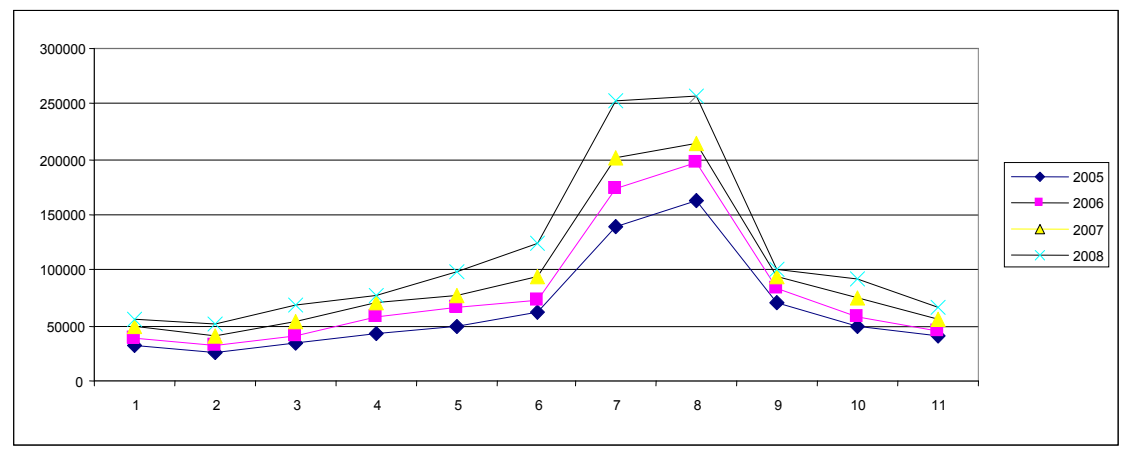

Figure 2: $\quad$ Number of visitors per month [13].

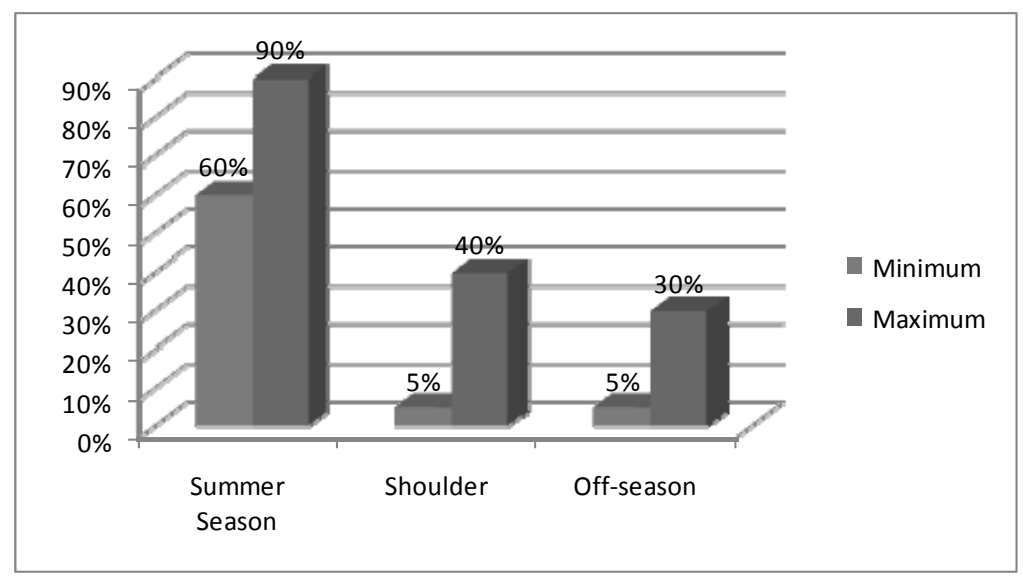

Figure 3: $\quad$ Fluctuation of the occupancy rate.

The overall occupancy rate (Figure 3) [11] for the area was estimated at the range $25-40 \%$. Hence, the occupancy rate for the summer season fluctuated among $60-90 \%$, while off-season 5-30\%. Actually, the highest occupancy rates were among hotels providing full service with recreational or business facilities. Off-season occupancy rate showed higher fluctuations due to the fact that hotels in Durres are closer to Tirana and offer more conference facilities, hence they create possibilities for organizing workshops, seminars etc.

The existing set of information concerning socio-economic characterisation and the qualitative evaluation of the territory were integrated with monitoring data relative to the seawater and air quality sample fields. As concerns seawater quality, the available data pointed out three levels of bacterial contamination ( 7 sampling points within the safety standards established by WHO/UNEP directives [14], 9 slightly polluted sampling points and 4 highly polluted ones). As concerns air quality, the main local air pollutants concentrations as well as ozone level are below the limits established by the European and Albanian 
legislation but particulate (TSP and $\mathrm{PM}_{10}$ ) concentrations are 2.5 - 3 times higher than the EU limits. Particulate emissions are mainly generated by the motor traffic, due also to the bad conditions of roads. Traffic generates also high acoustic pollution levels. There are no data concerning fresh water quality as well as the mineralogical and geochemical composition of the soil. However, the presence of chemical wastes (among which, lindane and chromium compounds) from an abandoned chemical plant as well as other uncontrolled dangerous wastes may cause a severe contamination of both ground water table and soil. In fact, the available data point out severe environmental pollution phenomena, due

Table 1: Assessment of tourism carrying capacity of Durres Bay according to a SWOT scheme.

\begin{tabular}{|c|c|}
\hline Strength points & Weakness points \\
\hline $\begin{array}{l}\text { New tourism destination } \\
\text { Natural and cultural heritage } \\
\text { Climate } \\
\text { Proximity to urban site with } \\
\text { advances services (airport, harbour, etc) } \\
\text { Proximity with many European } \\
\text { potential demand markets } \\
\text { Direct sea connections with Italy and } \\
\text { other European destinations. }\end{array}$ & $\begin{array}{l}\text { Uncontrolled urban } \\
\text { development which compromise the } \\
\text { natural resources and landscape } \\
\text { Massive environmental } \\
\text { impact of untreated solid waste } \\
\text { Relevant pollution of sea } \\
\text { water and fresh waters due to } \\
\text { contaminated discharge and } \\
\text { absence of sewage systems } \\
\text { - Scarce and intermittent } \\
\text { availability of electricity and } \\
\text { drinking water. environmental } \\
\text { Scarce territorial } \\
\text { education absence of } \\
\text { planning strategies and land use } \\
\text { plans Scarce development of } \\
\text { planned tourism activities } \\
\text { Scarce vocational training of } \\
\text { tour operators }\end{array}$ \\
\hline Opportunities & Threats \\
\hline $\begin{array}{l}\text { Possible improvement of actual } \\
\text { tourism infrastructures by adopting new } \\
\text { technologies based also on renewable } \\
\text { resources (solar PV and thermal plants, } \\
\text { phyto-remediation, composting, etc). } \\
\text { Interest of tour operators to } \\
\text { individuate and promote new tourism } \\
\text { destinations } \\
\text { Interesting site for a new demand } \\
\text { market } \\
\text { Possible development of alternative } \\
\text { tourism activities } \\
\text { Competition with other } \\
\text { Mediterranean destinations }\end{array}$ & $\begin{array}{l}\text { - Unrecoverable degeneration } \\
\text { of the environmental impacts } \\
\text { causing unsustainability of tourism } \\
\text { activities } \\
\text { - Absence of interventions for } \\
\text { the development of tourism } \\
\text { activities at short term. } \\
\text { - Hydro-geological risk caused } \\
\text { by the uncontrolled urban } \\
\text { development and exploitation of } \\
\text { mining resources }\end{array}$ \\
\hline
\end{tabular}


to contamination from industrial plants, unplanned waste disposal, uncontrolled discharge of water and sewage. The main indications emerging from the assessment of tourism carrying capacity are resumed in the following table, organised according to a SWOT scheme (Table 1) [12].

This analysis highlights the main infrastructural and environmental problems that affect the territory limiting its carrying capacity as well as the strength points for the exploitation of the tourism activities. At present, many actions and projects have been carried out, both at national and local level to overcome the most urgent problems. Moreover, some plans for a strategic development of the territory as well as for improving the waste management system will be implemented in a near future.

\section{The environmental certification}

In the framework of the project, a main issue concerned the definition of a specific environmental label for the tourism sector and its application on the territory [15].

Taking into account energy and environmental sustainability as leading standards with reference to the main themes investigated (air, soil, water, energy, waste treatment and disposal, main infrastructures) a National Environmental Label (NEL) was defined, identifying a set of minimum requirements in agreement with the European standards, necessary for the environmental certification of a territory and its accommodation structures. These minimum requirements considered as main factors the following:

- Absence of major criticalities concerning the management of environmental features or parameters of interest for the European Community, regulated by international agreements and structural drawbacks;

- Achievement of a list of fundamental requisites (at least 60\%) attesting the adequateness of infrastructures and services.

In fact, this National Environmental Label (NEL) considers the environmental sustainability of a main activity/process through its entire life cycle and could be therefore applied at different stages: on the whole territory, on different macroeconomic sectors as well as at corporate level, according to the accomplishment of a core set of fundamental requisites [15].

The environmental analysis put in evidence that the minimum requirements were not achieved at territorial level, preventing the territorial application of the devised environmental label. Nevertheless, tourism structures with high environmental standards could be certified on a voluntary basis (NEL-Corporate) $[16,17]$. In this framework eight selected structures were chosen as examples of best practice and certified by an environmental award. The indirect result was to encourage other structures to pursue higher quality standard, resulting in a general improvement of the territory that can forward the definition and the implementation of recovery plans and the achievement of the standards for awarding the NEL at municipal level. 


\section{Conclusions}

The overall objective of the project LIFE 06/TCY/AL/202 "Capacity Building for Sustainable Tourism Development" (2007-2009 was to incorporate sustainability concepts into tourism development, to identify and elaborate possible pathways for a sustainable growth of Albanian tourism sector, harmonised with environmental, territorial and economic development, and aimed at improving policies, institutional and entrepreneurial capacities.

The proposed methodology set the guidelines for implementing sustainable tourism policies, and, from a broader point of view, to improve the environmental quality of the study area and its infrastructures. Moreover, the innovative methodological approach can be applied similarly on other countries. In this context, considering the high potential of tourism sector for the economical and social development Albania can play the role of a pilot country for a know-how transfer process among adjacent territories, experiencing and sharing common problems and challenges. The implementation of the project on a local level highlighted once more the necessity of involving actively both local administrations and business as target and beneficiaries of the action, in order to make the outcomes actually effective.

\section{Acknowledgements}

This article has been produced with the financial contribution of the LIFE Third Country instrument of the European Community in the framework of the Project LIFE 06/TCY/AL/202 "Capacity Building for Sustainable Tourism Development" (http://www.cbstd.al) coordinated by the Albanian Centre for Business Research and Training of the Chamber of Commerce and Industry of Tirana (ACBRT/CCIT). We would like to thank the coordinator, Dr. Eng. Fatos Dega, for his valuable inputs that resulted in a successful development of the project

\section{References}

[1] Tourism Sustainability Group Action for more sustainable European tourism - Final Report, 2007.

[2] Bimonte, S., Punzo, L. F., A proposito di capacità di carico turistica una breve analisi teorica EdATS Working Papers Series Economia dell'Ambiente e del Turismo Sostenibile Osservatorio per il Turismo Sostenibile n. 4, 2005

[3] PAP/RAC: Guidelines for Carrying Capacity Assessment for Tourism in Mediterranean Coastal Areas. PAP-9/1997/G.1. Split, Priority Actions Programme Regional Activity Centre, 1997.

[4] PAP/RAC Guide to good practice in Tourism Carrying Capacity Assessment, Priority Actions Programme Regional Activity Centre, Split 2003. 
[5] Reinhard, J. (Editor). A Guidebook for Advanced Local Energy Planning, Bietigheim-Bissingen, Germany, Fachinstitut Gebäude Klima e.V. (FGK), 2000.

[6] C. Cosmi Operating Manual for the application of the CCA methodology Project LIFE 06/TCY/AL/202 "Capacity Building for Sustainable Tourism Development", 2008.

[7] Cosmi, C., Conte, E., Macchiato, M., Mangiamele, L., Marmo, G., Salvia, $\mathrm{M}$. The advanced local energy planning methodology (ALEP) for the development of air quality protection and recovery plans - case study Basilicata region (Southern Italy). Fresenius Environmental Bulletin, 9: pp. 673-682, 2000.

[8] European Environment Agency EEA core set of indicators Guide EEA Technical report No 1/2005 ISSN 1725-2237, 2005.

[9] European Environment Agency EEA Core Set of Indicators http://themes.eea.europa.eu/IMS/CSI

[10] Michelangeli, G., Sampaolesi S., Satta, A., Una strategia comune per lo sviluppo turistico sostenibile nelle aree costiere dell'Adriatico Progetto ASTA Azioni per la Sostenibilità del Turismo nell'Adriatico - Programma INTERREG IIIA Transfrontaliero Adriatico, 2006.

[11] Stringa, O., Kule, D., Duka, R., Tabaku, J., Haderi, S., Mema, F., Elmazi, L., Bakiu, V., Hashorva, A., Stringa, A., Shahini, B., Gorica, K., Kotorri, A., Rexhepi, P., Shehaj, E., Qefalia, A., Barrolli, E., Zerellari, M., Paloka, F., Panariti, N., Carrying Capacity Assessment For Tourism Development (Durrësi Bay-Albania) Project LIFE 06/TCY/AL/202 "Capacity Building for Sustainable Tourism Development" 2008.

[12] Cosmi, C., Fiore, S., Ragone, P., Guidelines for the development of sustainable tourism strategies in the area of the Durres Bay Project LIFE 06/TCY/AL/202 "Capacity Building for Sustainable Tourism Development", 2009.

[13] Albanian Ministry of Tourism www.mtkrs.gov.al

[14] UNEP/MAP/WHO: Municipal Wastewater Treatment Plans in Mediterranean Coastal Cities. MAP Technical Report Series No. 128, UNEP/MAP, Athens, 2000.

[15] Quality Program NEL - National Environmental Label Guidelines Project LIFE 06/TCY/AL/202 "Capacity Building for Sustainable Tourism Development", 2008.

[16] Task 6 Report Brand Building and Marketing Strategies for NEL Project LIFE 06/TCY/AL/202 "Capacity Building for Sustainable Tourism Development", 2008.

[17] Task 7 Report Guidelines on implementing sustainable tourism development principles by tourist service providers in Albania Project LIFE 06/TCY/AL/202 "Capacity Building for Sustainable Tourism Development", 2008. 